Check for updates

The BMJ

Cite this as: BMJ2020;371:m4291

http://dx.doi.org/10.1136/bmj.m4291

Published: 04 November 2020

\section{Covid-19: GPs are told to be ready to deliver vaccine from next month}

\section{Gareth lacobucci}

The NHS is preparing to deliver a covid-19 vaccine from as early as next month, the chief executive of NHS England has said.

Simon Stevens said that the NHS had reached an agreement with general practice leaders to mobilise now and be ready to start delivering a vaccine to patients in December. While it was most likely that a vaccine would be available in early 2021, he said, NHS England was writing to general practices this week to ensure that they are ready.

He explained that the NHS's current system for delivering flu vaccinations through GPs and pharmacists would be mobilised to deliver the new vaccine, with initial priority given to older people, health workers, and care home staff. Details of a new directed enhanced service, which will fund GPs and primary care networks to deliver covid vaccines, are expected to be announced shortly.

Earlier today (4 November) Stevens told a press briefing, "We expect that-given there are more than 200 vaccines in development-the first part of next year would be when some of those vaccines will be available to us.

"But we want to be ready, just in case they become available this side of Christmas. So, this week we've agreed with GPs and we'll be writing to every GP practice to set out the way in which they will play their part in getting coronavirus vaccines to patients, as and when it becomes available for the NHS."

He added that some logistics were still being worked through, including the fact that some vaccines have to be kept at $-70^{\circ} \mathrm{C}$ or lower, right up to the point of delivery. He said that the vaccine would be delivered by general practices and pharmacists, community vaccination centres located at Nightingale hospitals and other venues, and roving teams dispatched to care homes and other vulnerable populations.

\section{Ready and waiting}

The Joint Committee on Vaccination and Immunisation has recommended that a covid vaccine should first be given to care home residents and staff, followed by people aged over 80 and health and social workers, and then to the rest of the population in order of age and risk.

Stevens said, "At the moment, our working assumption is that the most vulnerable people-the elderly, folks living in care homes, and health and social care staff-will be front of the queue, but with others who are at higher risk in short order, followed potentially by a much wider group thereafter.

But that really is determined by the science and by the vaccines that come along. Our job is just to make sure that we are ready and waiting and able to fire the starting gun, as and when."

A Department of Health and Social Care spokesperson said, "While there are no certainties in the development, production, and timing of new vaccines, there is a possibility a covid-19 vaccine could be available in the UK in the first part of 2021.

"It will only be rolled out once proven to be safe and effective through robust clinical trials and approved by the MHRA [Medicines and Healthcare Products Regulatory Agency]. Once approved, the NHS stands ready to begin the vaccination programme to those most at risk, before being rolled out more widely.” 